\title{
Identification and characterization of tumor suppressor and oncogenic miRNAs in gastric cancer
}

\author{
ZHAOFENG CHEN ${ }^{1,2^{*}}$, XIAOGUANG LIU ${ }^{1 *}$, ZENAN HU $^{1 *}$, YUPING WANG $^{2}$, MIN LIU $^{1,2}$, \\ XIAOJUN LIU ${ }^{1}$, HAILONG LI ${ }^{1}$, RUI JI ${ }^{1,2}$, QINHONG GUO ${ }^{1,2}$ and YONGNING ZHOU ${ }^{1,2}$ \\ ${ }^{1}$ Division of Gastroenterology and Hepatology, The First Hospital of Lanzhou University; \\ ${ }^{2}$ Key Laboratory for Gastrointestinal Diseases of Gansu, Lanzhou University, Lanzhou, Gansu 730000, P.R. China
}

Received May 13, 2014; Accepted April 27, 2015

DOI: $10.3892 / \mathrm{ol} .2015 .3179$

\begin{abstract}
The aim of the present study was to screen for and identify microRNAs (miRNAs/miRs) that are associated with gastric cancer and to clarify the role of these miRNAs in gastric cancer. Thus, the differential expression of a panel of miRNAs in two pairs of gastric cancer tissues and their matched adjacent healthy tissues was investigated by performing a microarray analysis. To verify the results of this screen, 56 gastric cancer tissues were analyzed for the selected miRNAs using reverse transcription-quantitative polymerase chain reaction (RT-qPCR). The association between the expression of a specific miRNA and the clinical data relating to the tissue samples [including age, gender, tumor size, tumor node metastasis (TNM) stage and lymph-node metastasis] were subsequently examined. A total of 31 differentially expressed miRNAs were identified in the miRNA array. Using RT-qPCR to verify these results, it was determined that 10 miRNAs exhibited high mRNA expression levels and 13 miRNAs exhibited a low expression in the gastric cancer tissue samples, while 8 miRNAs did not demonstrate an association with gastric cancer. Thus, the microarray and RT-qPCR results demonstrated $74.2 \%$ (23/31 miRNAs) agreement. The association between the 23 miRNAs and the clinicopathological characteristics of the gastric cancer samples was investigated. It was identified that the expression levels of miR-551b-3p, miR-133b, miR-100-5p and miR-363-3p were significantly downregulated in the gastric cancer tissues, and this downregulation was closely correlated with the degree of differentiation (i.e., tumor grade), TNM stage and lymph-node metastasis $(\mathrm{P}<0.05)$. By contrast, the
\end{abstract}

Correspondence to: Professor Yongning Zhou, Division of Gastroenterology and Hepatology, The First Hospital of Lanzhou University, 1 Dong-Gang West Road, Lanzhou, Gansu 730000, P.R. China

E-mail: czf0616@163.com

*Contributed equally

Key words: gastric cancer, microRNA, clinical pathology expression of miR-215 was significantly upregulated in the gastric cancer tissues, and its expression level was correlated with tumor differentiation, TNM stage and lymph-node metastasis $(\mathrm{P}<0.05)$. Furthermore, miR-200a-3p was upregulated in the gastric cancer tissues and its expression was significantly more prevalent in male patients compared with female patients $(\mathrm{P}<0.05)$. miR-429 was upregulated in the gastric cancer tissues and its expression was significantly higher in patients who were $>50$ years of age $(\mathrm{P}<0.05)$. These data indicate that a number of these miRNAs may be important in the development of gastric cancer. In particular, miR-551b-3p, miR-133b, miR-100-5p and miR-363-3p may act as tumor suppressors in the development of gastric cancer. By contrast, miR-215 appears to exhibit oncogenic properties and promote the development of gastric cancer. In addition, the abnormal expression of miR-200a-3p may be associated with gender, while the abnormal expression of miR-429 may be associated with age in patients with gastric cancer. However, additional studies are required to delineate the underlying mechanisms of the association, and to explore their potential as valid biomarkers in the diagnosis, classification and prognosis of gastric cancer.

\section{Introduction}

Gastric cancer has one of the highest incidence rates of any cancer type worldwide. In 2008, 989,600 new cases of gastric cancer were reported globally, accounting for $8 \%$ of all cancer cases and resulting in 738,000 mortalities (10\% of all cancer-related mortalities) (1). The current treatment strategy for gastric cancer is surgical resection. Surgical resection is associated with a $\leq 90 \%$ postoperative 5 -year survival rate for patients diagnosed with early-stage gastric cancer. However, the majority of patients with gastric cancer are diagnosed at an advanced stage, and, thus, are no longer suitable to undergo radical surgery, resulting in a decreased 5-year survival rate of $11-40 \%$. Therefore, improvement in the early-stage diagnosis of gastric cancer, the development of novel molecular-targeted therapies, and the identification of early indicators of cancer metastasis and recurrence are important research topics. These issues may be resolved by improved investigation into the pathogenesis of gastric cancer as well as the finding of specific molecular targets for gastric cancer therapy. 
microRNAs (miRNAs/miRs) are small, non-coding, single-stranded RNAs (length, 19-25 nt) that are expressed by plants and animals. miRNAs inhibit the transcription and translation of specific target genes by incomplete base pairing with their target mRNA molecules (2). Over 2,000 types of miRNA have been found thus far, and numerous studies are currently being conducted to identify more (http://www.mirbase.org/). Previous studies have demonstrated that miRNAs regulate the expression of approximately two-thirds of all proteins, and almost every vital cell activity, including development, apoptosis, cell proliferation and division (3).

miRNAs are extensively correlated with specific pathological processes, such as tumor development, metastasis and tolerance, and $\sim 50 \%$ of miRNAs are located within tumor-associated fragile sites, oncogenes or tumor suppressor breakpoints (4). Furthermore, various studies $(3,4)$ have indicated that miRNAs have been well-conserved during evolution, as demonstrated by their strict spatial and temporal specificity. The majority of aberrantly expressed miRNAs in tumors can be detected in the peripheral blood, and these serum miRNAs can tolerate multi-gelation, variations in $\mathrm{pH}$ and treatment with DNAases. In addition, miRNA appears to be more stable following treatment with RNAases compared with mRNA $(5,6)$. In consideration of the aforementioned studies, miRNAs appear to exhibit properties that potentially enable their exploitation as biological targets in tumor diagnostics, prognostic evaluation and treatment.

Previous studies have screened for and identified a subset of miRNAs that are associated with gastric cancer, indicating their extensive participation in the development and progression of gastric cancer $(7,8)$. However, the biological function and mechanisms of many of these miRNAs remains unknown. Therefore, the present study aimed to screen for additional miRNAs that may be associated with gastric cancer using gene chromatin immunoprecipitation (ChIP) technology. In addition, the present study aimed to identify the association between these miRNAs, and the clinicopathological characteristics of gastric cancer to demonstrate the specific functions and mechanisms of these miRNAs during tumor development. To the best of our knowledge, the present study provides novel hypotheses regarding the mechanism of gastric cancer as well as proposing possible future targeted treatment strategies. Subsequent to their verification, these specific markers of gastric cancer may serve as criteria in the diagnosis and prognostic evaluation of gastric cancer.

\section{Materials and methods}

Patients and tissue sample collection. The present study was approved by the Ethics Committee of the First Hospital of Lanzhou University (Lanzhou, China). Tissues were collected from 56 gastric cancer patients who received surgical treatment at the Wuwei Tumor Hospital of Gansu (Wuwei, China) between October 2009 and April 2010. Matched gastric cancer and adjacent healthy $(n=56)$ tissue samples were obtained for use in the present study subsequent to written informed consent being provided by all the patients, and samples were stored at $-80^{\circ} \mathrm{C}$ immediately after surgical resection. The sixth edition of the International Union Against Cancer and the American Joint Committee on Cancer pathological staging systems were used to determine the tumor node metastasis (TNM) stage of the tissues samples. In addition, clinical data were recorded for all patients, including gender, age, tumor diameter, tumor location, degree of differentiation, TNM stage and lymph-node metastasis. The samples were obtained from 32 male patients and 24 female patients; therefore, the male:female ratio was 1.3:1. Furthermore, the patients were aged between 35 and 76 years, and the median age was 56 years. No patients received radiotherapy or chemotherapy prior to undergoing surgery.

miRNA microarray. RNAiso Plus (Takara Bio, Inc., Otsu, Japan) was used to treat the cancer and adjacent healthy tissue samples from two representative patients, according to the manufacturer's instructions. The microarray experiments were performed by the Shanghai Bohao Biotechnological Co., Ltd (Shanghai, China) using an 8*60 K human miRNA microarray chip (version 18.0), a microarray scanner, Feature Extraction software (version 10.7) and GeneSpring GX software (version 11.0; Agilent Technologies, Inc., Santa Clara, CA, USA), according to the manufacturer's instructions.

Reverse transcription-quantitative polymerase chain reaction $(R T-q P C R)$. A PrimeScript ${ }^{\circledR}$ First Strand cDNA Synthesis kit and miRNA qPCR primer mix (Takara Bio, Inc.) were used to perform the qRT-PCR assay, according to the manufacturer's instructions.

Statistical analysis. SPSS software (version 15.0; SPSS, Inc., Chicago, IL, USA) was used to perform the data analysis. T-tests were used to evaluate the differences between the mean values. Values were presented as the mean \pm standard error of the mean. $\mathrm{P}<0.05$ was considered to indicate a statistically significant difference.

\section{Results}

Screening for gastric cancer-associated miRNAs. The 8*60 K human miRNA microarray chip (version 18.0; Agilent Technologies, Inc), which contains 1,907 human miRNA genes, was used to screen for miRNAs that are differentially expressed between gastric cancer and healthy adjacent tissues.

The screening criteria used to compare the gastric cancer tissue samples with the adjacent healthy mucosa samples were: i) In the two paired samples, the expression of a miRNA was upregulated or downregulated $>2$-fold; and ii) in every four samples, there were a minimum of two samples with a signal value of $>6$. It was identified that the expression levels of 31 miRNAs were abnormal in the gastric cancer tissues. Of these, 14 miRNAs were overexpressed and 17 were underexpressed (Table I). Clustering analysis was subsequently performed for all 31 abnormally expressed miRNAs (Fig. 1).

Verification of the expression of the selected miRNAs in gastric cancer tissue. RT-qPCR was performed to select 31 miRNA targets from the ChIP, and to examine the miRNA expression of the 56 gastric cancer tissues and healthy adjacent mucosa.

The results demonstrated that 23/31 miRNAs were differentially expressed between the gastric cancer and healthy tissue samples. Ten miRNAs were overexpressed and 13 miRNAs demonstrated a lower expression in the gastric cancer samples 
Table I. Differential expression of preliminarily screened miRNAs in gastric cancer.

\begin{tabular}{|c|c|c|}
\hline No. & Gene name & $\begin{array}{c}\text { Expression in gastric } \\
\text { cancer tissue }\end{array}$ \\
\hline 1 & Hsa-miR-192-5p & Upregulated \\
\hline 2 & Hsa-miR-200b-3p & Upregulated \\
\hline 3 & Hsa-miR-200c-3p & Upregulated \\
\hline 4 & Hsa-miR-19b-3p & Upregulated \\
\hline 5 & Hsa-miR-141-3p & Upregulated \\
\hline 6 & Hsa-miR-215 & Upregulated \\
\hline 7 & Hsa-miR-194-5p & Upregulated \\
\hline 8 & Hsa-miR-200a-3p & Upregulated \\
\hline 9 & Hsa-miR-148a-3p & Upregulated \\
\hline 10 & Hsa-miR-429 & Upregulated \\
\hline 11 & Hsa-miR-142-3p & Upregulated \\
\hline 12 & Hsa-miR-7-5p & Upregulated \\
\hline 13 & Hsa-miR-146a-5p & Upregulated \\
\hline 14 & Hsa-miR-96-5p & Upregulated \\
\hline 15 & Hsa-miR-145-5p & Downregulated \\
\hline 16 & Hsa-miR-27b-3p & Downregulated \\
\hline 17 & Hsa-miR-143-3p & Downregulated \\
\hline 18 & Hsa-miR-23b-3p & Downregulated \\
\hline 19 & Hsa-miR-125b-5p & Downregulated \\
\hline 20 & Hsa-let-7c & Downregulated \\
\hline 21 & Hsa-miR-1 & Downregulated \\
\hline 22 & Hsa-miR-133b & Downregulated \\
\hline 23 & Hsa-miR-100-5p & Downregulated \\
\hline 24 & Hsa-miR-99a-5p & Downregulated \\
\hline 25 & Hsa-miR-30a-5p & Downregulated \\
\hline 26 & Hsa-miR-145-3p & Downregulated \\
\hline 27 & Hsa-miR-143-5p & Downregulated \\
\hline 28 & Hsa-miR-363-3p & Downregulated \\
\hline 29 & Hsa-miR-365a-3p & Downregulated \\
\hline 30 & Hsa-miR-193a-3p & Downregulated \\
\hline 31 & Hsa-miR-551b-3p & Downregulated \\
\hline
\end{tabular}

miRNA/miR, microRNA.

compared with the healthy tissue samples. No significant difference was identified for the remaining 8 miRNAs. Thus, the sensitivity of the results from the two experiments was $74.2 \%$ (23/31 miRNAs; Table II).

Association between the identified miRNAs and the clinicopathological characteristics of gastric cancer. The correlation between the expression of the 23 selected miRNAs in the gastric cancer samples and associated clinicopathological characteristics were analyzed. The results identified that four miRNAs, miR-142-3p, miR-146a-5p, miR-145-5p and miR-1, were not associated with the following clinicopathological characteri stics: Gender, age, tumor size, differentiation/grade, clinical stage and lymph-node metastasis. However, the remaining 19 miRNAs were significantly associated with lymph-node metastasis, and miR-551b-3p, miR-133b, miR-100-5p, miR-363-3p and miR-215 were significantly correlated

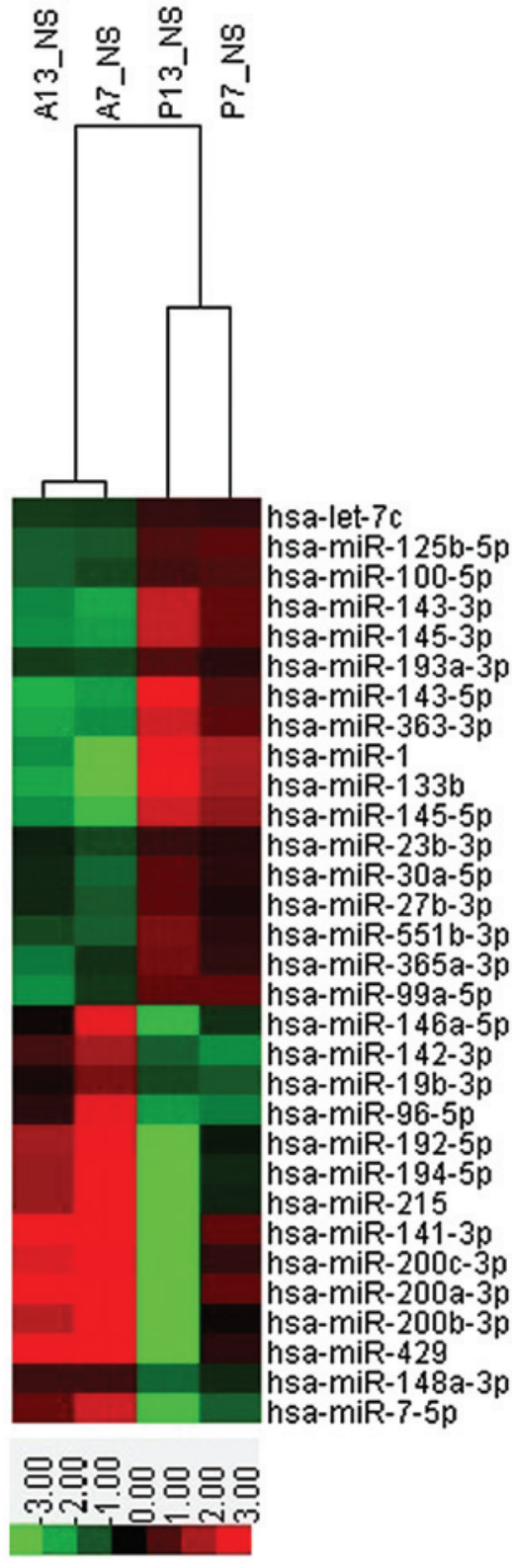

Figure 1. Clustering analysis diagram of gene chip. miR, microRNA. Red indicates upregulated gene expression and green indicates downregulated gene expression.

with tumor differentiation/grade and TNM stage $(\mathrm{P}<0.05$; Tables III-VII). In addition, it was identified that the abnormal expression of miR-200a-3p and miR-429 was significantly associated with the gender and age of the gastric cancer patients, respectively $(\mathrm{P}<0.05$; Tables VIII-IX).

\section{Discussion}

miRNAs regulate endogenous gene expression in humans, affecting numerous cell functions (for example, growth, differentiation, apoptosis and stress responses) by downregulating the expression of target genes (9). miRNAs were found to be important in the process of tumor development, and multiple miRNAs may be directly associated with the development of human tumors (for example, pancreatic, colorectal, gastric, liver, breast and lung cancer, and lymphoma) (10-12). The role 
Table II. Expression of screened miRNAs in gastric cancer versus adjacent healthy tissue samples.

miRNA expression, $\Delta \mathrm{Ct}($ mean $\pm \mathrm{SE})$

\begin{tabular}{|c|c|c|c|c|c|}
\hline & & & & & \\
\hline No. & Gene name & Tumor tissue & $\begin{array}{c}\text { Adjacent } \\
\text { healthy tissue }\end{array}$ & $\begin{array}{l}\text { Change in expression } \\
\text { in gastric cancer }\end{array}$ & P-value \\
\hline 1 & Hsa-miR-192-5p & $-1.967 \pm 0.812$ & $1.648 \pm 0.611$ & $\mathbf{\Delta}$ & $0.001^{*}$ \\
\hline 2 & Hsa-miR-200b-3p & $-1.644 \pm 0.369$ & $0.134 \pm 0.676$ & $\Delta$ & $0.024^{*}$ \\
\hline 3 & Hsa-miR-200c-3p & $-0.476 \pm 0.347$ & $1.242 \pm 0.688$ & $\Delta$ & $0.029^{*}$ \\
\hline 4 & Hsa-miR-19b-3p & $3.153 \pm 0.312$ & $3.149 \pm 0.351$ & & 0.994 \\
\hline 5 & Hsa-miR-141-3p & $3.572 \pm 0.619$ & $3.533 \pm 0.503$ & & 0.962 \\
\hline 6 & Hsa-miR-215 & $3.859 \pm 0.407$ & $6.590 \pm 0.622$ & $\Delta$ & $0.000^{*}$ \\
\hline 7 & Hsa-miR-194-5p & $-1.178 \pm 0.299$ & $0.897 \pm 0.592$ & $\Delta$ & $0.002^{*}$ \\
\hline 8 & Hsa-miR-200a-3p & $1.726 \pm 0.320$ & $3.511 \pm 0.673$ & $\Delta$ & $0.018^{*}$ \\
\hline 9 & Hsa-miR-148a-3p & $0.709 \pm 0.330$ & $0.707 \pm 0.451$ & & 0.997 \\
\hline 10 & Hsa-miR-429 & $2.699 \pm 0.362$ & $4.585 \pm 0.477$ & $\Delta$ & $0.012^{*}$ \\
\hline 11 & Hsa-miR-142-3p & $0.903 \pm 0.296$ & $1.784 \pm 0.290$ & $\Delta$ & $0.036^{*}$ \\
\hline 12 & Hsa-miR-7-5p & $3.220 \pm 0.333$ & $4.833 \pm 0.491$ & $\Delta$ & $0.008^{*}$ \\
\hline 13 & Hsa-miR-146a-5p & $2.219 \pm 0.269$ & $3.437 \pm 0.476$ & $\Delta$ & $0.028^{*}$ \\
\hline 14 & Hsa-miR-96-5p & $4.640 \pm 0.317$ & $5.048 \pm 0.487$ & & 0.484 \\
\hline 15 & Hsa-miR-145-5p & $-0.384 \pm 0.329$ & $-2.605 \pm 0.275$ & $\nabla$ & $0.000^{*}$ \\
\hline 16 & Hsa-miR-27b-3p & $4.938 \pm 0.215$ & $4.671 \pm 0.291$ & & 0.462 \\
\hline 17 & Hsa-miR-143-3p & $-1.205 \pm 0.337$ & $-3.392 \pm 0.199$ & $\nabla$ & $0.000^{*}$ \\
\hline 18 & Hsa-miR-23b-3p & $-1.295 \pm 0.691$ & $-2.159 \pm 0.792$ & & 0.413 \\
\hline 19 & Hsa-miR-125b-5p & $-0.605 \pm 0.498$ & $-1.327 \pm 0.379$ & & 0.251 \\
\hline 20 & Hsa-let-7c & $-0.098 \pm 0.225$ & $-0.669 \pm 0.252$ & & 0.094 \\
\hline 21 & Hsa-miR-1 & $18.273 \pm 0.447$ & $11.937 \pm 0.516$ & $\nabla$ & $0.000^{*}$ \\
\hline 22 & Hsa-miR-133b & $8.942 \pm 0.356$ & $3.620 \pm 0.939$ & $\nabla$ & $0.000^{*}$ \\
\hline 23 & Hsa-miR-100-5p & $2.324 \pm 0.332$ & $1.152 \pm 0.204$ & $\nabla$ & $0.003^{*}$ \\
\hline 24 & Hsa-miR-99a-5p & $2.102 \pm 0.336$ & $0.873 \pm 0.211$ & $\nabla$ & $0.003^{*}$ \\
\hline 25 & Hsa-miR-30a-5p & $0.992 \pm 0.289$ & $0.160 \pm 0.272$ & $\nabla$ & $0.039^{*}$ \\
\hline 26 & Hsa-miR-145-3p & $2.221 \pm 0.313$ & $0.444 \pm 0.224$ & $\nabla$ & $0.000^{*}$ \\
\hline 27 & Hsa-miR-143-5p & $4.236 \pm 0.317$ & $2.384 \pm 0.271$ & $\nabla$ & $0.000^{*}$ \\
\hline 28 & Hsa-miR-363-3p & $6.890 \pm 0.309$ & $2.703 \pm 0.892$ & $\nabla$ & $0.000^{*}$ \\
\hline 29 & Hsa-miR-365a-3p & $3.936 \pm 0.261$ & $2.535 \pm 0.349$ & $\nabla$ & $0.002^{*}$ \\
\hline 30 & Hsa-miR-193a-3p & $6.188 \pm 0.279$ & $5.236 \pm 0.319$ & $\nabla$ & $0.027^{*}$ \\
\hline 31 & Hsa-miR-551b-3p & $8.733 \pm 0.309$ & $6.449 \pm 0.356$ & $\nabla$ & $0.000^{*}$ \\
\hline
\end{tabular}

$\Delta \mathrm{Ct}$ indicates the relative miRNA expression level (the higher the $\Delta \mathrm{Ct}$ value, the lower the miRNA expression). miRNA/miR, microRNA; $\mathrm{Ct}$, cycle threshold; SE, standard error.

of miRNAs in tumor pathogenesis is complex, as they can regulate or suppress tumor-associated genes to promote or inhibit cancer, respectively. In addition, miRNAs may serve as oncogenes or tumor suppressor genes and, thus, participate in the development of various types of cancer. Within a particular tissue type, one miRNA targets multiple genes, as each target mRNA can potentially interact with multiple miRNAs. Therefore, miRNAs compose a complex regulatory network that may contribute to the development of tumors (13).

Significant progress has been made in the field of miRNA. For example, previous studies have screened for and identified a variety of functional miRNAs in a number of different tumor types. The identification of these miRNAs may facilitate the elucidation of the mechanisms of tumorigenesis, and may provide novel targets for early diagnosis and treatment $(14,15)$.
It is possible that numerous miRNAs have yet to be identified; therefore, the correlation between the expression of specific miRNAs and tumors is unknown. However, significant progress has been made in this field.

In the current study, miRNA ChIP technology was used to evaluate the expression levels of miRNAs in carcinoma and adjacent healthy tissue from two patients who were diagnosed with gastric cancer to identify the miRNAs that are associated with this cancer type. A total of 31 miRNAs were identified that exhibited differential expression levels between the tumor and healthy tissue samples. RT-qPCR was subsequently performed to verify the differential expression of these miRNAs in samples from 56 patients diagnosed with gastric cancer. The results demonstrated that only 23 miRNAs exhibited significantly differential expression while the remaining 8 miRNAs 
Table III. Association between the expression of miR-551b-3p and clinicopathological characteristics of gastric cancer.

\begin{tabular}{lrrr}
\hline & & $\begin{array}{c}\text { Expression of } \\
\text { miR-551b-3p, }\end{array}$ & \\
Variable & $\mathrm{n}(\%)$ & median \pm range & P-value \\
\hline Gender & & & 0.857 \\
$\quad$ Male & $32(57)$ & $8.684 \pm 0.417$ & \\
Female & $24(43)$ & $8.798 \pm 0.470$ & \\
Age, years & & & 0.785 \\
$\quad$ 50 & $18(32)$ & $8.857 \pm 0.362$ & \\
$>50$ & $38(68)$ & $8.674 \pm 0.425$ & \\
Tumor size, cm & & & 0.360 \\
$\quad 55$ & $31(55)$ & $8.475 \pm 0.445$ & \\
$>5$ & $25(45)$ & $9.052 \pm 0.420$ & \\
Degree of differentiation & & & $0.015^{*}$ \\
Well and moderately & $17(30)$ & $7.148 \pm 0.601$ & \\
Poorly & $39(70)$ & $9.988 \pm 0.356$ & \\
TNM stage & & & $0.039^{*}$ \\
I/II & $27(48)$ & $5.902 \pm 0.436$ & \\
III/IV & $29(52)$ & $8.575 \pm 0.442$ & \\
Lymph-node status & & & $0.013^{*}$ \\
No metastasis & $6(11)$ & $8.470 \pm 0.310$ & \\
Metastasis & $50(89)$ & $10.924 \pm 0.937$ & \\
\hline
\end{tabular}

miR, microRNA; TNM, tumor node metastasis.

Table IV. Association between the expression of miR-133b and clinicopathological parameters of gastric cancer.

\begin{tabular}{|c|c|c|c|}
\hline Variable & $\begin{array}{c}\text { Cases, } \\
\text { n }(\%)\end{array}$ & $\begin{array}{c}\text { Expression of } \\
\text { miR-133b } \\
\text { median } \pm \text { range }\end{array}$ & P-value \\
\hline Gender & & & 0.675 \\
\hline Male & $32(57)$ & $8.811 \pm 0.506$ & \\
\hline Female & $24(43)$ & $9.117 \pm 0.493$ & \\
\hline Age, years & & & 0.720 \\
\hline$\leq 50$ & $18(32)$ & $8.754 \pm 0.381$ & \\
\hline$>50$ & $38(68)$ & $9.031 \pm 0.495$ & \\
\hline Tumor size, $\mathrm{cm}$ & & & 0.606 \\
\hline$\leq 5$ & $31(55)$ & $8.774 \pm 0.504$ & \\
\hline$>5$ & $25(45)$ & $9.149 \pm 0.502$ & \\
\hline Degree of differentiation & & & $0.047^{*}$ \\
\hline Well and moderately & $17(30)$ & $6.637 \pm 0.739$ & \\
\hline Poorly & $39(70)$ & $9.475 \pm 0.402$ & \\
\hline TNM stage & & & $0.043^{*}$ \\
\hline $\mathrm{I} / \mathrm{II}$ & $27(48)$ & $6.952 \pm 0.576$ & \\
\hline III/IV & $29(52)$ & $8.933 \pm 0.440$ & \\
\hline Lymph-node status & & & $0.025^{*}$ \\
\hline No metastasis & $6(11)$ & $8.667 \pm 0.337$ & \\
\hline Metastasis & $50(89)$ & $11.231 \pm 0.591$ & \\
\hline
\end{tabular}

miR, microRNA; TNM, tumor node metastasis.
Table V. Association between the expression of miR-100-5p and clinicopathological parameters of gastric cancer.

\begin{tabular}{|c|c|c|c|}
\hline Variable & $\begin{array}{c}\text { Cases, } \\
\mathrm{n}(\%)\end{array}$ & $\begin{array}{l}\text { Expression of } \\
\text { miR-100-5p, } \\
\text { median } \pm \text { range }\end{array}$ & P-value \\
\hline Gender & & & 0.700 \\
\hline Male & $32(57)$ & $2.215 \pm 0.491$ & \\
\hline Female & $24(43)$ & $1.950 \pm 0.440$ & \\
\hline Age, years & & & 0.523 \\
\hline$\leq 50$ & $18(32)$ & $1.785 \pm 0.412$ & \\
\hline$>50$ & $38(68)$ & $2.251 \pm 0.456$ & \\
\hline Tumor size, $\mathrm{cm}$ & & & 0.343 \\
\hline$\leq 5$ & $31(55)$ & $1.812 \pm 0.453$ & \\
\hline$>5$ & $25(45)$ & $2.460 \pm 0.500$ & \\
\hline Degree of differentiation & & & $0.049^{*}$ \\
\hline Well and moderately & $17(30)$ & $1.630 \pm 0.556$ & \\
\hline Poorly & $39(70)$ & $3.507 \pm 0.409$ & \\
\hline TNM stage & & & $0.037^{*}$ \\
\hline $\mathrm{I} / \mathrm{II}$ & $27(48)$ & $1.351 \pm 0.583$ & \\
\hline III/IV & $29(52)$ & $3.869 \pm 0.360$ & \\
\hline Lymph-node status & & & $0.001^{*}$ \\
\hline No metastasis & $6(11)$ & $1.740 \pm 0.295$ & \\
\hline Metastasis & $50(89)$ & $5.108 \pm 0.561$ & \\
\hline
\end{tabular}

miR, microRNA; TNM, tumor node metastasis.

Table VI. Association between the expression of miR-363-3p and clinicopathological parameters of gastric cancer.

\begin{tabular}{|c|c|c|c|}
\hline Variable & $\begin{array}{l}\text { Cases, } \\
\mathrm{n}(\%)\end{array}$ & $\begin{array}{l}\text { Expression of } \\
\text { miR-363-3p, } \\
\text { median } \pm \text { range }\end{array}$ & P-value \\
\hline Gender & & & 0.515 \\
\hline Male & $32(57)$ & $3.786 \pm 0.352$ & \\
\hline Female & $24(43)$ & $4.134 \pm 0.391$ & \\
\hline Age, years & & & 0.773 \\
\hline$\leq 50$ & $18(32)$ & $4.046 \pm 0.499$ & \\
\hline$>50$ & $38(68)$ & $3.883 \pm 0.308$ & \\
\hline Tumor size, $\mathrm{cm}$ & & & 0.686 \\
\hline$\leq 5$ & $31(55)$ & $3.839 \pm 0.373$ & \\
\hline$>5$ & $25(45)$ & $4.055 \pm 0.363$ & \\
\hline Degree of differentiation & & & $0.035^{*}$ \\
\hline Well and moderately & $17(30)$ & $2.010 \pm 0.637$ & \\
\hline Poorly & $39(70)$ & $4.837 \pm 0.351$ & \\
\hline TNM stage & & & $0.046^{*}$ \\
\hline $\mathrm{I} / \mathrm{II}$ & $27(48)$ & $2.914 \pm 0.651$ & \\
\hline III/IV & $29(52)$ & $4.941 \pm 0.282$ & \\
\hline Lymph-node status & & & $0.021^{*}$ \\
\hline No metastasis & $6(11)$ & $2.729 \pm 0.248$ & \\
\hline Metastasis & $50(89)$ & $5.657 \pm 0.139$ & \\
\hline
\end{tabular}

miR, microRNA; TNM, tumor node metastasis. 
Table VII. Association between the expression of miR-215 and clinicopathological parameters of gastric cancer.

\begin{tabular}{|c|c|c|c|}
\hline Variable & $\begin{array}{c}\text { Cases, } \\
\mathrm{n}(\%)\end{array}$ & $\begin{array}{l}\text { Expression of } \\
\text { miR-215, } \\
\text { median } \pm \text { range }\end{array}$ & P-value \\
\hline Gender & & & 0.134 \\
\hline Male & $32(57)$ & $4.750 \pm 0.840$ & \\
\hline Female & $24(43)$ & $3.437 \pm 0.441$ & \\
\hline Age, years & & & 0.285 \\
\hline$\leq 50$ & $18(32)$ & $3.479 \pm 0.553$ & \\
\hline$>50$ & $38(68)$ & $4.366 \pm 0.596$ & \\
\hline Tumor size, cm & & & 0.171 \\
\hline$\leq 5$ & $31(55)$ & $4.448 \pm 0.561$ & \\
\hline$>5$ & $25(45)$ & $3.355 \pm 0.571$ & \\
\hline Degree of differentiation & & & $0.039^{*}$ \\
\hline Well and moderately & $17(30)$ & $5.408 \pm 0.704$ & \\
\hline Poorly & $39(70)$ & $3.056 \pm 0.500$ & \\
\hline TNM stage & & & $0.047^{*}$ \\
\hline $\mathrm{I} / \mathrm{II}$ & $27(48)$ & $4.985 \pm 0.674$ & \\
\hline III/IV & $29(52)$ & $3.042 \pm 0.484$ & \\
\hline Lymph-node status & & & $0.001^{*}$ \\
\hline No metastasis & $6(11)$ & $7.583 \pm 0.386$ & \\
\hline Metastasis & $50(89)$ & $3.413 \pm 0.383$ & \\
\hline
\end{tabular}

miR, microRNA; TNM, tumor node metastasis.

Table VIII.Association between the expression of miR-200a-3p and clinicopathological parameters of gastric cancer.

\begin{tabular}{|c|c|c|c|}
\hline Variable & $\begin{array}{c}\text { Cases, } \\
\mathrm{n}(\%)\end{array}$ & $\begin{array}{l}\text { Expression of } \\
\text { miR-200a-3p, } \\
\text { median } \pm \text { range }\end{array}$ & P-value \\
\hline Gender & & & $0.048^{*}$ \\
\hline Male & $32(57)$ & $1.178 \pm 0.377$ & \\
\hline Female & $24(43)$ & $2.456 \pm 0.527$ & \\
\hline Age, years & & & 0.376 \\
\hline$\leq 50$ & $18(32)$ & $2.143 \pm 0.674$ & \\
\hline$>50$ & $38(68)$ & $1.528 \pm 0.351$ & \\
\hline Tumor size, cm & & & 0.909 \\
\hline$\leq 5$ & $31(55)$ & $1.759 \pm 0.470$ & \\
\hline$>5$ & $25(45)$ & $1.684 \pm 0.430$ & \\
\hline Degree of differentiation & & & 0.458 \\
\hline Well and moderately & $17(30)$ & $1.885 \pm 0.394$ & \\
\hline Poorly & $39(70)$ & $1.361 \pm 0.552$ & \\
\hline TNM stage & & & 0.377 \\
\hline $\mathrm{I} / \mathrm{II}$ & $27(48)$ & $2.023 \pm 0.568$ & \\
\hline III/IV & $29(52)$ & $1.449 \pm 0.325$ & \\
\hline Lymph-node status & & & $0.003^{*}$ \\
\hline No metastasis & $6(11)$ & $4.379 \pm 0.597$ & \\
\hline Metastasis & $50(89)$ & $1.407 \pm 0.280$ & \\
\hline
\end{tabular}

miR, microRNA; TNM, tumor node metastasis.
Table IX. Association between the expression of miR-429 and clinicopathological parameters of gastric cancer.

\begin{tabular}{|c|c|c|c|}
\hline Variable & $\begin{array}{c}\text { Cases, } \\
\mathrm{n}(\%)\end{array}$ & $\begin{array}{l}\text { Expression of } \\
\text { miR-429, } \\
\text { median } \pm \text { range }\end{array}$ & P-value \\
\hline Gender & & & 0.208 \\
\hline Male & $32(57)$ & $2.272 \pm 0.334$ & \\
\hline Female & $24(43)$ & $3.130 \pm 0.637$ & \\
\hline Age, years & & & $0.047^{*}$ \\
\hline$\leq 50$ & $18(32)$ & $3.602 \pm 0.763$ & \\
\hline$>50$ & $38(68)$ & $2.184 \pm 0.317$ & \\
\hline Tumor size, $\mathrm{cm}$ & & & 0.746 \\
\hline$\leq 5$ & $31(55)$ & $2.739 \pm 0.531$ & \\
\hline$>5$ & $25(45)$ & $2.518 \pm 0.368$ & \\
\hline Degree of differentiation & & & 0.705 \\
\hline Well and moderately & $17(30)$ & $2.445 \pm 0.521$ & \\
\hline Poorly & $39(70)$ & $2.725 \pm 0.426$ & \\
\hline TNM stage & & & 0.363 \\
\hline $\mathrm{I} / \mathrm{II}$ & $27(48)$ & $2.959 \pm 0.584$ & \\
\hline III/IV & $29(52)$ & $2.343 \pm 0.351$ & \\
\hline Lymph-node status & & & 0.074 \\
\hline No metastasis & $6(11)$ & $3.169 \pm 0.756$ & \\
\hline Metastasis & $50(89)$ & $2.216 \pm 0.262$ & \\
\hline
\end{tabular}

miR, microRNA; TNM, tumor node metastasis.

demonstrated no significant difference in expression between the gastric cancer and healthy tissue samples. Therefore, the results from the microarray and RT-qPCR experiments were $74.2 \%$ in agreement, indicating error in the miRNA array. The two primary reasons for this experimental error may be: i) The limited number of test samples analyzed; and ii) the shortcomings of the gene ChIP technique, including its relatively poor stability and reproducibility, as well as the fact that false positive detection cannot be avoided (16).

Correlation analysis between the expression levels of the 23 differentially expressed miRNAs and the associated clinicopathological characteristics was performed. It was identified that four miRNAs, miR-142-3p, miR-146a-5p, miR-145-5p and miR-1, were not associated with the following analyzed clinicopathological parameters: Gender, age, tumor size, differentiation/grade, clinical stage and lymph-node metastasis. The remaining 19 miRNAs were associated with lymph-node metastasis, of which miR-551b-3p, miR-133b, miR-100-5p, miR-363-3p and miR-215 were significantly associated with tumor differentiation/grade and TNM stage $(\mathrm{P}<0.05)$, indicating that these miRNAs are possibly involved in the invasion and metastasis of gastric cancer. Notably, the abnormal expression levels of miR-200a-3p and miR-429 were significantly associated with the gender and age of the gastric cancer patients in the present study, respectively $(\mathrm{P}<0.05)$. According to epidemiological statistics, the incidence of gastric cancer significantly increases with age, with the peak age of gastric cancer occurrence ranging between 50 and 80 years. Furthermore, male individuals are 
1.5- to 2.5-fold more likely to develop gastric cancer compared with females (1). Thus, identification of the significant association between abnormal miR-200a-3p and miR-429 expression in gastric cancer tissue, and respective differences in age and gender, may be useful during diagnosis.

A recent study demonstrated that the expression of miR-551a is downregulated in gastric cancer tissues and cells, and that miR-551a may inhibit cell invasion and migration by downregulating the expression of phosphatase of regenerating liver-3 (17). This finding indicates that miR-551a is important in gastric cancer invasion and migration. Similarly, the present study identified that miR-551b-3p exhibits different expression levels in gastric cancer tissues compared with healthy tissues. Furthermore, the expression of miR-551b-3p appears to be significantly associated with the tumor differentiation/grade, TNM stage and lymph-node metastasis. These results indicate that miR-551b-3p is an important factor in the development of gastric cancer, as well as in the invasion and metastasis of this cancer type.

The miR-133 family consists of miR-133a-1, miR-133a-2 and miR-133b. Originally, a number of studies determined that miR-133 is critical in regulating heart and skeletal muscle development $(18,19)$. However, a more recent study demonstrated that miR-133 is aberrantly expressed in tumors, and that $\mathrm{miR}-133 \mathrm{a} / \mathrm{b}$ can inhibit the proliferation, and metastasis of bladder and prostate cancer by regulating the expression of the epidermal growth factor receptor $(20,21)$. In addition, previous studies have observed a significant downregulation of miR-133a/b in head and neck neoplasms, lung cancer, esophageal cancer, colon cancer, renal carcinoma, prostate cancer, and other malignancies (22-25). The present study indicated that miR-133b may act as a tumor suppressor while regulating the invasion and metastasis of cancer cells.

Previous studies have indicated that the expression level of miR-100 varies between tumor types and, therefore, this miRNA may have different functions in different cancer types. For example, miR-100 expression is downregulated in lung, cervical, ovarian and bladder cancer, and acts as a tumor suppressor (26-28). However, in various types of cancer, such as acute myeloid leukemia, miR-100 is upregulated and functions as an oncogene (29). The present study indicated that miR-100-5p is downregulated in gastric cancer, and may be involved in the infiltration and metastasis of gastric cancer.

Studies regarding the function of $\mathrm{miR}-363-3 \mathrm{p}$ in the development of cancer are limited. Sun et al (30) demonstrated that miR-363-3p expression is downregulated in squamous cell carcinoma of the head and neck (SCCHN), and is involved in the development and metastasis of SCCHN via the regulation of podoplanin. Furthermore, Georgieva et al (31) used high-throughput sequencing to detect the abnormal expression of miR-363 in uterine fibroids. However, to the best of our knowledge, no studies have thus far investigated the function of miR-363-3p in gastric cancer. The present study demonstrated that miR-363-3p is significantly downregulated in gastric cancer, and that its expression level is significantly associated with the degree of tumor differentiation, TNM stage and lymph node metastasis $(\mathrm{P}<0.05$. Therefore, the current results indicate that $\mathrm{miR}-364-3 \mathrm{p}$ is a novel molecule that may be involved in the infiltration and metastasis of gastric cancer.
miR-215 functions differently in different tumor types. It was initially identified to be a P53-induced miRNA that functions as a tumor suppressor by regulating the expression of various proteins involved in cell cycle checkpoints (32). Alternative studies have demonstrated that miR-215 downregulates thymidylate synthetase, dihydrofolate reductase, thymidylate synthetase and denticleless E3 ubiquitin protein ligase homolog, and functions in the development of chemotherapy resistance $(33,34)$. Furthermore, the upregulation of miR-215 was observed in esophageal, kidney and colon cancer (35-37). In contrast to its role in other solid tumors, miR-215 functions as an oncogene in gastric cancer by promoting cell proliferation and cancer cell metastasis (38-40); however, the underlying mechanism has yet to be defined. In agreement with previous reports, the current study demonstrated that the relatively high expression of miR-215 in gastric cancer is significantly associated with the degree of tumor differentiation, TNM stage and lymph node metastasis $\mathrm{P}<0.05$ ). Therefore, miR-215 could potentially be used as a biomarker in the diagnosis of gastric cancer due to its significantly upregulated expression in this cancer type $(\mathrm{P}<0.05)$.

In conclusion, the present study successfully identified a number of miRNAs that are involved in the development of gastric cancer. However, additional studies are required to delineate the underlying mechanisms of the association, and to explore their potential as valid biomarkers in the diagnosis, classification and prognosis of gastric cancer.

\section{Acknowledgements}

The present study was supported by the National Natural Science Foundation of China (grant no. 81372145); the Research Fund of Personnel training plan of West Light (grant no. 201218), Chinese Academy of Sciences; and the Gansu Provincial Natural Science Foundation (grant no. 1308RJZA223).

\section{References}

1. Jemal A, Bray F, Center MM, et al: Global cancer statistics. CA Cancer J Clin 61: 69-90, 2011.

2. Treiber T, Treiber N and Meister G: Regulation of microRNA biogenesis and function. Thromb Haemost 107: 605-610, 2012.

3. Anglicheau D, Muthukumar T and Suthanthiran M: MicroRNAs: small RNAs with big effects. Transplantation 90: 105-112, 2010.

4. Farazi TA, Hoell JI, Morozov P and Tuschl T: MicroRNAs in human cancer. Adv Exp Med Biol 774: 1-20, 2013.

5. Mitchell PS, Parkin RK, Kroh EM, et al: Circulating microRNAs as stable blood-based markers for cancer detection. Proc Natl Acad Sci USA 105: 10513-10518, 2008.

6. Ng EK, Chong WW, Jin H, et al: Differential expression of microRNAs in plasma of patients with colorectal cancer: a potential marker for colorectal cancer screening. Gut 58: 1375-1381, 2009.

7. Wang HJ, Ruan HJ,He XJ,et al: MicroRNA-101 is down-regulated in gastric cancer and involved in cell migration and invasion. Eur J Cancer 46: 2295-2303, 2010.

8. Yao Y, Suo AL, Li ZF, et al: MicroRNA profiling of human gastric cancer. Mol Med Rep 2: 963-970, 2009.

9. Ambros V: MicroRNA pathways in flies and worms: growth, death, fat, stress and timing. Cell 113: 673-676, 2003.

10. Rachagani S, Kumar S and Batra SK: MicroRNA in pancreatic cancer: pathological, diagnostic and therapeutic implications. Cancer Lett 292: 8-16, 2010.

11. Liu R, Zhang C, Hu Z, et al: A five-microRNA signature identified from genome-wide serum microRNA expression profiling serves as a fingerprint for gastric cancer diagnosis. Eur J Cancer 47: 784-791, 2011.

12. Xiong Y, Fang JH, Yun JP, et al: Effects of MicroRNA-29 on apoptosis, tumorigenicity, and prognosis of hepatocellular carcinoma. Hepatology 51: 836-845, 2010. 
13. Synnergren J, Améen C, Lindahl A, et al: Expression of microRNAs and their target mRNAs in human stem cell-derived cardiomyocyte clusters and in heart tissue. Physiol Genomics 43: 581-594, 2011.

14. Calin GA and Croce CM: MicroRNA signatures in human cancers. Nat Rev Cancer 6: 857-866, 2006.

15. Lovat F, Valeri N and Croce CM: MicroRNAs in the pathogenesis of cancer. Semin Oncol 38: 724-733, 2011.

16. Simon R: Challenges of microarray data and the evaluation of gene expression profile signatures. Cancer Invest 26: 327-332, 2008.

17. Li Z, Cao Y, Jie Z, et al: miR-495 and miR-551a inhibit the migration and invasion of human gastric cancer cells by directly interacting with PRL-3. Cancer Lett 323: 41-47, 2012.

18. Yin VP, Lepilina A, Smith A and Poss KD: Regulation of zebrafish heart regeneration by miR-133. Dev Biol 365: 319-327, 2012.

19. Chen JF, Mandel EM, Thomson JM, et al: The role of microRNA-1 and microRNA-133 in skeletal muscle proliferation and differentiation. Nat Genet 38: 228-233, 2006.

20. Zhou Y, Wu D, Tao J, et al: MicroRNA-133 inhibits cell proliferation, migration and invasion by targeting epidermal growth factor receptor and its downstream effector proteins in bladder cancer. Scand J Urol 47: 423-432, 2013.

21. Tao J, Wu D, Xu B, et al: MicroRNA-133 inhibits cell proliferation, migration and invasion in prostate cancer cells by targeting the epidermal growth factor receptor. Oncol Rep 27 $1967-1975,2012$

22. Kinoshita T, Nohata N, Watanabe-Takano H, et al: Actin-related protein $2 / 3$ complex subunit 5 (ARPC5) contributes to cell migration and invasion and is directly regulated by tumor-suppressive microRNA-133a in head and neck squamous cell carcinoma. Int J Oncol 40: 1770-1778, 2012

23. Moriya Y, Nohata N, Kinoshita T, et al: Tumor suppressive microRNA-133a regulates novel molecular networks in lung squamous cell carcinoma. J Hum Genet 57: 38-45, 2012.

24. Kawakami K, Enokida H, Chiyomaru T, et al: The functional significance of miR-1 and miR-133a in renal cell carcinoma. Eur J Cancer 48: 827-836, 2012.

25. Wu ZS, Wang CQ, Xiang R, et al: Loss of miR-133a expression associated with poor survival of breast cancer and restoration of miR-133a expression inhibited breast cancer cell growth and invasion. BMC Cancer 12: 51, 2012.

26. Liu J, Lu KH, Liu ZL, et al: MicroRNA-100 is a potential molecular marker of non-small cell lung cancer and functions as a tumor suppressor by targeting polo-like kinase 1. BMC Cancer 12: 519, 2012.

27. Li BH, Zhou JS, Ye F, et al: Reduced miR-100 expression in cervical cancer and precursors and its carcinogenic effect through targeting PLK1 protein. Eur J Cancer 47: 2166-2174, 2011.
28. Peng DX, Luo M, Qiu LW, et al: Prognostic implications of microRNA-100 and its functional roles in human epithelial ovarian cancer. Oncol Rep 27: 1238-1244, 2012.

29. Zheng YS, Zhang H, Zhang XJ, et al: MiR-100 regulates cell differentiation and survival by targeting RBSP3, a phosphatase-like tumor suppressor in acute myeloid leukemia. Oncogene 31: 80-92, 2012.

30. Sun Q, Zhang J, Cao W, et al: Dysregulated miR-363 affects head and neck cancer invasion and metastasis by targeting podoplanin. Int J Biochem Cell Biol 45: 513-520, 2013.

31. Georgieva B, Milev I, Minkov I, et al: Characterization of the uterine leiomyoma microRNAome by deep sequencing. Genomics 99: 275-281, 2012.

32. Georges SA, Biery MC, Kim SY, et al: Coordinated regulation of cell cycle transcripts by p53-Inducible microRNAs, miR-192 and miR-215. Cancer Res 68: 10105-10112, 2008.

33. Song B, Wang Y, Titmus MA, et al: Molecular mechanism of chemoresistance by miR-215 in osteosarcoma and colon cancer cells. Mol Cancer 9: 96, 2010.

34. Boni V, Bitarte N, Cristobal I, et al: miR-192/miR-215 influence 5-fluorouracil resistance through cell cycle-mediated mechanisms complementary to its post-transcriptional thymidilate synthase regulation. Mol Cancer Ther 9: 2265-2275, 2010.

35. Wijnhoven BP, Hussey DJ, Watson DI, et al; South Australian Oesophageal Research Group: MicroRNA profiling of Barrett's oesophagus and oesophageal adenocarcinoma. Br J Surg 97: 853-861, 2010.

36. White NM, Khella HW, Grigull J, et al: miRNA profiling in metastatic renal cell carcinoma reveals a tumour-suppressor effect for miR-215. Br J Cancer 105: 1741-1749, 2011.

37. Faltejskova P, Svoboda M, Srutova K, et al: Identification and functional screening of microRNAs highly deregulated in colorectal cancer. J Cell Mol Med 16: 2655-2666, 2012.

38. Jin Z, Selaru FM, Cheng Y, et al: MicroRNA-192 and -215 are upregulated in human gastric cancer in vivo and suppress ALCAM expression in vitro. Oncogene 30: 1577-1585, 2011.

39. Ueda T, Volinia S, Okumura H, et al: Relation between microRNA expression and progression and prognosis of gastric cancer: a microRNA expression analysis. Lancet Oncol 11: $136-146,2010$.

40. Tsukamoto Y, Nakada C, Noguchi T, Tanigawa M, et al: MicroRNA-375 is downregulated in gastric carcinomas and regulates cell survival by targeting PDK1 and 14-3-3zeta. Cancer Res 70: 2339-2349, 2010. 